\section{Fluorotelomer Acids are More Toxic than Perfluorinated Acids}

\author{
MICHELLE M . (MACDONALD) PHILLIPS , \\ MARY JOYCE A. DINGLASAN-PANLILIO, \\ SCOTTA. MABURY, \\ KEITH R. SOLOMON ${ }^{\dagger}$ AND \\ PAUL K. SIBLEY*, † \\ Department of Environmental Biology, University of Guelph, \\ Edmund C. Bovey Building, Guelph, Ontario, Canada, N1G \\ 2W1, and Department of Chemistry, University of Toronto, 80 \\ Saint George Street, Toronto, Ontario, Canada, M5S 3 H6
}

Saturated and unsaturated fluorotelomer carboxylic acids have been identified as intermediates in the degradation of fluorotelomer alcohols to perfluorinated carboxylic acids (PFCAs). Although surface waters are the likely environmental sink for telomer acids, no fate or toxicity data exist for this matrix. We assessed the acute toxicity of the $4: 2,6: 2$, 8:2, and 10:2 saturated (FTCA) and unsaturated (FTUCA) fluorotelomer carboxylic acids to Daphnia magna, Chironomus tentans, and Lemna gibba. In general, toxicity increased with increasing fluorocarbon (FC) chain length, particularly for telomer acids of $\geq 8 \mathrm{FCs}$. In addition, the FTCAs were generally more toxic than the corresponding FTUCAs. Acute EC50s ranged from $0.025 \mathrm{mg} / \mathrm{L}(0.04 \mu \mathrm{mol} / \mathrm{L})$ for $D$. magna (10:2 FTCA, immobility) to $63 \mathrm{mg} / \mathrm{L}(167 \mu \mathrm{mol} / \mathrm{L})$ for $C$. tentans (6:2 FTCA, growth). While chain-length trends observed in the current study agree with those previously reported for PFCAs, the toxicity thresholds generated here are up to 10000 times smaller. Our data provide the first evidence that PFCA precursors are more toxic than the PFCAs themselves.

\section{Introduction}

Recent scientific evidence implicates fluorotelomer alcohols (FTOHs) as a substantial source of the global perfluorinated carboxylic acid (PFCA) (1-3) contamination observed in human blood (4), wildlife (5-7), water and sediments $(5,8$, 9 ). The FTOHs are predominantly used as intermediates in the manufacture of polymers for soil, oil, and water repellent surface treatment applications $(10,11)$. Annual global FTOH production is estimated at $11-14$ million $\mathrm{kg}(11,12)$. Individual FTOHs are distinguished by their molecular ratio of fluorinated to hydrogenated carbon atoms (e.g., 8:2 FTOH).

Environmental releases of FTOHs may occur as a result of degradation of commercial and industrial polymeric products or as fugitive emissions resulting from their failure to become covalently linked to polymers during the manufacturing process $(2,12-14)$. FTOHs have been quantified in the troposphere over North America at mean concentrations of $11-171 \mathrm{pg} / \mathrm{m}^{3}(13,15)$. Atmospheric oxidation of the FTOHs results in the production of corresponding saturated and unsaturated fluorotelomer carboxylic acids (FTCAs and FTUCAs) $(1,16)$. The predicted lower volatility and greater

\footnotetext{
* Corresponding author phone: (519) 824-4120, x52707; fax: (519) 837-0442; e-mail: psibley@uoguelph.ca.

† University of Guelph.

‡ University of Toronto.
}

water solubility of the telomer acids compared with their FTOH counterparts (17) is expected to result in wet atmospheric deposition of telomer acids in surface waters. Although no surface water concentrations have been reported to date, the 8:2 and 10:2 FTCAs and FTUCAs have been detected in rainwater $(<0.07-8.6 \mathrm{ng} / \mathrm{L})$ collected across Canada and the Northeastern U.S. $(17,18)$. Furthermore, the 8:2 and 10:2 telomer acids have been detected in aquatic mammals, including bottlenose dolphins (19) and arctic ringed seals (20) at concentrations of approximately $1 \mathrm{ng} / \mathrm{g}$ and up to $9.6 \mathrm{ng} / \mathrm{g}$, respectively. In addition to atmospheric deposition, other sources of telomer acids to aquatic environments may include the biotic and abiotic degradation of FTOHs released to wastewater treatment facilities as a result of routine activities such as carpet and upholstery cleaning $(2,3,21,22)$.

Although evidence for the presence of fluorotelomer acids in aquatic systems has increased in recent years, studies to assess potential effects of these compounds have not been conducted. The goal of this study, therefore, was to assess the toxicity of telomer acids to aquatic organisms. The specific objectives of the study were to assess the acute laboratory toxicity of the $4: 2,6: 2,8: 2$, and 10:2 FTCAs and FTUCAs to three common freshwater species: the pelagic microcrustacean Daphnia magna, the benthic macroinvertebrate Chironomus tentans, and the floating macrophyte Lemna gibba. Toxicity thresholds for the eight telomer acids studied were compared to assess the impact of both fluorinated carbon chain length and saturation status of the $\alpha-\beta$ carbon bond (between the first and second carbons in the chain adjacent to the carboxylic group) on relative toxicity within and between species. Figure 1 provides the structure of the 8:2 FTCA and FTUCA as an example of the general structure of all of the telomer acids investigated in the current study.

\section{Experimental Procedures}

Experimental procedures are briefly described below. Additional details are available as Supporting Information.

Chemicals. The 4:2, 6:2, 8:2, and 10:2 FTCAs and FTUCAs were synthesized at the University of Toronto using methods described by Achilefu et al. (23), and were $>98 \%$ pure.

Test Organisms. Daphnia magna brood stocks were obtained from Stantec Consulting Inc. (Guelph, ON, Canada) approximately 9 months prior to test initiation. Chironomus tentans egg cases were supplied by the United States Environmental Protection Agency's Office of Research and Development (Duluth, MN) approximately 8 months prior to test initiation. Lemna gibba (G-3) was originally obtained from the University of Waterloo (Waterloo, ON, Canada). Subsequent culturing of test organisms in our laboratory followed established methods for Daphnia (24), Chironomus (25), and Lemna $(26,27)$ species.

Toxicity Assays. Since no previous toxicity testing had been done with telomer acids, preliminary assays were conducted with each of the eight acids and all three aquatic species to establish toxicity ranges. The general methodology and endpoints assessed were the same as for the definitive assays (i.e., D. magna, $48 \mathrm{~h}$ survival and immobility; C. tentans, 10 day survival and growth; L. gibba, 7 day frond number and dry biomass). The greatest nominal concentrations used in these initial assays ranged from approximately $18 \mathrm{mg} / \mathrm{L}$ for the $10: 2$ acids to $100 \mathrm{mg} / \mathrm{L}$ for the $4: 2$ and 6:2 acids. Telomer acids with LC50s within the range of concentrations tested in these preliminary assays were tested in subsequent acute definitive assays. In the preliminary tests with telomer acid 


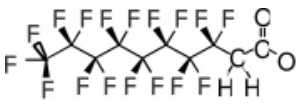

8:2 FTCA
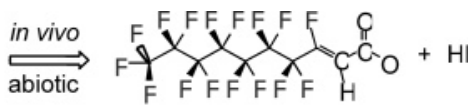

8:2 FTUCA
FIGURE 1. Structure of fluorotelomer carboxylic acids investigated in this study, with the 8:2 telomer acid shown as an example. The 4:2, 6:2, and 10:2 telomer acids vary only in the number of perfluorinated carbons. The transformation from FTCA to FTUCA occurs both in vivo and abiotically in the environment.

concentrations of $0-100 \mathrm{mg} / \mathrm{L}, D$. magna displayed no sensitivity to the $4: 2$ or 6:2 FTCAs and FTUCAs, while $C$. tentans was insensitive to both the 4:2 FTCA and FTUCA and the 6:2 FTUCA. Therefore, no further testing was performed with these shorter chain telomer acids for either invertebrate. Conversely, L. gibba showed sensitivity to all of the telomer acids in the preliminary assays and all were further tested in definitive assays.

The following sections provide a brief overview of the assays conducted. Additional detail regarding assay conditions, test solution preparation, and residue analyses are available as Supporting Information.

Daphnia magna 48 h Assays. Definitive assays were conducted in accordance with American Society for Testing and Materials (ASTM) (28) and Environment Canada (29) standards for $48 \mathrm{~h}$ acute toxicity tests with $D$. magna. Briefly, assays were performed in a walk-in environmental chamber held at $20 \pm 2^{\circ} \mathrm{C}$ with a 16:8 h light:dark photoperiod. Neonates of $\leq 24 \mathrm{~h}$ in age were randomly transferred with wide-bore plastic pipettes into individual replicates consisting of $200 \mathrm{~mL}$ of telomer acid-spiked ASTM reconstituted hard ("recon") water in a $250 \mathrm{~mL}$ polypropylene beaker. Each assay was conducted with five replicates/treatment and 8-10 animals/replicate. Actual concentrations tested in D. magna definitive assays were $0,0.3,0.8,2.5,5.1,12.3,26.0$, and 57.4 $\mathrm{mg} / \mathrm{L}$ for the 8:2 FTCA; 0, 1.6, 2.1, 3.6, 6.6, 11.5, 19.0, and 24.2 $\mathrm{mg} / \mathrm{L}$ for the 8:2 FTUCA; 0, 0.01, 0.02, 0.03, 0.04, 0.06, 0.1, 0.2, $0.5,1.0$, and $1.9 \mathrm{mg} / \mathrm{L}$ for the 10:2 FTCA; and 0, 0.02, 0.03, $0.07,0.1,0.2,0.3,0.4,0.9,1.0,1.8,3.9,6.4,12.5$, and 15.5 for the 10:2 FTUCA. Test solutions were not renewed over the duration of the assay. Endpoints evaluated at the end of the $48 \mathrm{~h}$ exposure period were survival and immobility.

Chironomus tentans 10 Day Assays. Definitive assays were conducted following ASTM standards for 10 day toxicity testing using $C$. tentans (30). All assays were performed in a walk-in environmental chamber maintained at $23 \pm 2{ }^{\circ} \mathrm{C}$ with a photoperiod of 16:8 h light:dark. Replicates consisted of $50 \mathrm{~mL}$ of medium-grain $(250-499 \mu \mathrm{m})$ culture sand in a $250 \mathrm{~mL}$ polypropylene beaker overlain with approximately $240 \mathrm{~mL}$ of telomer acid-spiked ASTM recon water. Individual 10 day old larvae were randomly transferred into each replicate using wide-bore plastic pipettes. Replicates were fed $1.5 \mathrm{~mL}$ of Tetrafin fish flake slurry ( $4 \mathrm{~g} / \mathrm{L}$ ) daily and were gently aerated via rubber tubing through plastic pipet tips attached to the top of each test vessel. Each assay was conducted with five replicates/treatment and 8-10 animals/ replicate. Static-renewal of test solutions began on day 2, and took place every $48 \mathrm{~h}$ thereafter (25). Under this regime, dissolved oxygen concentrations (measured prior to each renewal) remained consistently $>5 \mathrm{mg} / \mathrm{L}$ for the duration of all tests, more than double the minimum requirement of 2.5 $\mathrm{mg} / \mathrm{L}$ (30). Regular telomer acid residue analyses were conducted to ensure adequate quantification of potential variation in exposure concentrations using the static-renewal approach. Actual concentrations tested in C. tentans definitive assays were $0,0.3,1.5,1.9,2.9,3.3,5.1,8.8,10.0,14.0,18.0$, 22.6 , and $33.4 \mathrm{mg} / \mathrm{L}$ for the 8:2 FTCA; 0, 2.2, 3.9, 6.8, 7.2, 13.7, 18.7, and $24.0 \mathrm{mg} / \mathrm{L}$ for the 8:2 FTUCA; 0, 2.0, 3.1, 7.9, 8.0, 10.4, and $16.3 \mathrm{mg} / \mathrm{L}$ for the 10:2 FTCA; and 0, 0.3, 0.5, 0.9,
$1.3,1.9,2.3,3.5,4.3,6.6,8.4,9.8,13.0$, and 16.1 for the $10: 2$ FTUCA.

Endpoints evaluated at the end of the 10 day exposure were survival and growth. Live larvae were removed from the substrate, enumerated, and grouped by replicate for measurement of growth. Growth, measured as ash-free dry weight (AFDW), was determined as the mean difference between the dry weight $\left(60^{\circ} \mathrm{C}\right.$ for $\left.24 \mathrm{~h}\right)$ and ashed weight $\left(550{ }^{\circ} \mathrm{C}\right.$ for $2 \mathrm{~h}$ ) of replicates within a treatment $(30)$.

Lemna gibba 7 Day Assays. Definitive assays were conducted in accordance with ASTM standards (27) for 7 day static renewal toxicity tests with Lemna gibba. All assays were performed axenically in an environmental chamber held at $25 \pm 2{ }^{\circ} \mathrm{C}$ under constant cool white fluorescent light (approximately 6200 lux). Each replicate consisted of $10 \mathrm{~mL}$ of telomer-acid-spiked half-strength Hutner's media (26) in a $60 \times 15 \mathrm{~mm}$ polystyrene petri dish (Fisher Scientific Ltd., Pittsburgh, PA). At test initiation, two plants (eight fronds in total) were transferred to each Petri dish. Test solutions were renewed twice (days 2 and 4 ) over the course of each assay by transferring plants into new petri dishes prepared with fresh test solutions. Each assay was conducted with three replicates/treatment. Actual concentrations tested in L. gibba definitive assays were $0,10.2,10.7,16.9,24.9,38.7$, and $50.9 \mathrm{mg} / \mathrm{L}$ for the 4:2 FTCA; 0, 4.6, 7.2, 9.8, 14.9, 19.5, and $24.9 \mathrm{mg} / \mathrm{L}$ for the 4:2 FTUCA; 0, 0.4, 1.6, 2.4, 4.2, 6.0, and $11.8 \mathrm{mg} / \mathrm{L}$ for the 6:2 FTCA; 0, 3.5, 4.9, 7.6, 10.8, 14.8, and $19.5 \mathrm{mg} / \mathrm{L}$ for the $6: 2$ FTUCA; 0, 0.4, 0.5, 0.9, 1.2, 1.7, and $2.6 \mathrm{mg} / \mathrm{L}$ for the $8: 2$ FTCA; 0, 0.4, 0.6, 0.9, 1.1, 1.6, and $2.1 \mathrm{mg} / \mathrm{L}$ for the 8:2 FTUCA; 0, 0.4, 0.5, 0.9, 1.2, 1.7, and $2.6 \mathrm{mg} / \mathrm{L}$ for the 10:2 FTCA; and 0, 0.01, 0.2, 0.5, 2.0, 3.2, and 4.3 for the 10:2 FTUCA. Endpoints evaluated at the end of the 7 day test period were total frond number and dry (24 $\mathrm{h}$ at $60^{\circ} \mathrm{C}$ ) biomass.

Residue Sampling. Residue analyses were performed for definitive assays only. Test solutions were sampled in $500 \mu \mathrm{L}$ aliquots, which were added to an equal volume of methanol in $1.5 \mathrm{~mL}$ polypropylene flat top microcentrifuge tubes (Fisher Scientific Ltd., Pittsburgh, PA) and stored at $5^{\circ} \mathrm{C}$ until they were analyzed. Daphnia magna and C. tentans exposure solutions were sampled at the initiation and end of each corresponding assay period. Freshly prepared test solutions of the greatest concentration were also sampled every $48 \mathrm{~h}$, prior to renewal. In addition, $48 \mathrm{~h}$-old test solutions from all replicates were pooled to produce one composite sample per treatment, just prior to renewal on day 5. Lemna gibba freshly prepared test solutions were sampled once at the initiation of each $7 \mathrm{~d}$ assay. Samples were also taken at the end of the $7 \mathrm{~d}$ exposure period for the 8:2 FTCA, 10:2 FTCA, and FTUCA assays.

Residue Analyses. All samples were analyzed using a Waters 616 pump with a 600 controller (Waters Ltd., Milford, MA) coupled to a Micromass Quattro Micro LC tandem mass spectrometer (Micromass UK Ltd., Cheshire UK) operating in negative electrospray ionization mode. Chromatographic separations were performed using an Ace 3 C18 column (15 $\mathrm{cm} \times 2.1 \mathrm{~mm}, 3 \mu \mathrm{m}$ ) (Life Sciences Inc., Peterborough, ON). Isocratic elution was used at a flow rate of $150 \mu \mathrm{L} / \mathrm{min}$ with mobile phase comprised of 75:25 $10 \mathrm{mmol}$ ammonium acetate in methanol and $10 \mathrm{mmol}$ aqueous ammonium acetate. Samples were injected at a volume of $20 \mu \mathrm{L}$ using a Waters 717 autosampler.

Mass spectral analysis was optimized by tuning the mass spectrometer using a $500 \mu \mathrm{g} / \mathrm{L}$ standard solution of each of the compounds of interest. The capillary voltage was set to $3 \mathrm{kV}$ while the cone voltage varied from 10 to $15 \mathrm{kV}$ depending on the compound. The dwell time was $0.2 \mathrm{~s}$. The source block and desolvation temperatures were 110 and $250{ }^{\circ} \mathrm{C}$, respectively, while the desolvation gas flow rate was $250 \mathrm{~L} / \mathrm{hr}$. Argon was used as the collision gas $\left(3.0 \times 10^{-3} \mathrm{mBar}\right)$ and 


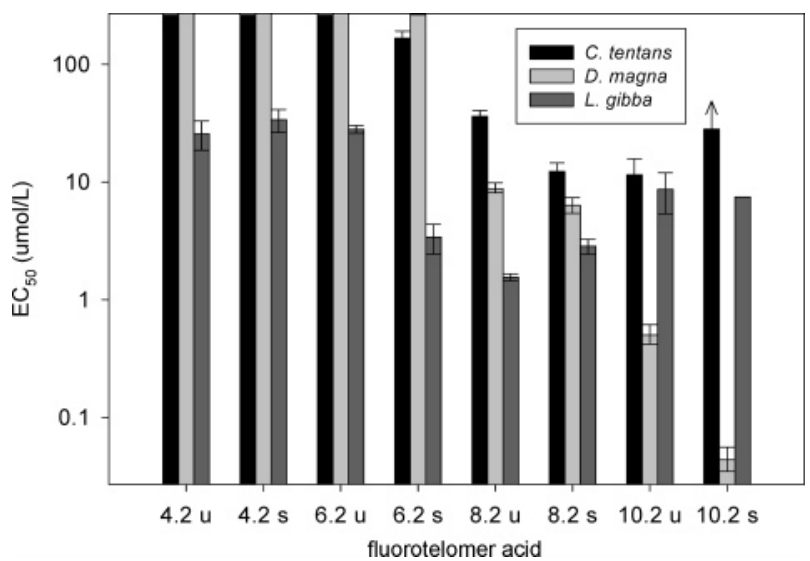

FIGURE 2. Relative toxicity (EC50s) of eight saturated (s) and unsaturated (u) fluorotelomer carboxylic acids to Chironomus tentans, Daphnia magna, and Lemna gibba for ash-free dry weight, immobility, and dry weight, respectively. Error bars represent $95 \%$ confidence intervals. Toxicity thresholds in excess of the greatest concentration tested are indicated either by bars extending to the top of the graph (4:2 u, 4:2 s, 6:2 u, 6:2 s) or by an arrow at the top of the bar (10:2 s).

collision energies were varied for optimal detection of each compound analyzed.

External calibrations were used with standards ranging from $5-500 \mu \mathrm{g} / \mathrm{L}$. Calibration curves were linear with $R^{2}$ typically $>0.99$. Samples with concentrations below $5 \mu \mathrm{g} / \mathrm{L}$ were concentrated using solid-phase extraction (SPE) and eluted with $1 \mathrm{~mL}$ of methanol prior to analysis while samples with greater than $1000 \mu \mathrm{g} / \mathrm{L}$ concentrations were further diluted.

Statistical Analyses. Data were evaluated using linear and nonlinear regression techniques to generate lethal and effect concentrations $\left(\mathrm{LC}_{x}\right.$ and $\mathrm{EC}_{x}$ ) resulting in 10, 25, and $50 \%$ differences in measured endpoints from control treatments (31). $\mathrm{LC}_{x}$ and $\mathrm{EC}_{x}$ values were calculated using actual measured concentrations. Binominal (i.e., mobility, survival) data were evaluated using the Proc Probit procedure for probit analyses in the SAS System for Windows, Version 8.2 (SAS Institute, Cary, NC). Continuous data (i.e., growth) were analyzed using nonlinear regression techniques (31) and the Proc Nonlin procedure in SAS.

\section{Results and Discussion}

Experimental results are briefly described below, with additional details provided as Supporting Information. Minimum acceptable criteria were met for all assays used to estimate toxicity thresholds. Minimum acceptable criteria specific to the test organisms include $\geq 90 \%$ and $70 \%$ control survival for $D$. magna and C. tentans, respectively (28); a minimum ash-free dry weight of $0.48 \mathrm{mg}$ for individual $C$. tentans larvae (30); and at least an 8-fold increase in frond number for $L$. Gibba in each control test chamber (27).

Actual measured concentrations were used to determine acute toxicity thresholds for the three aquatic species and eight telomer acids presented in Figure 2. To compare relative toxicity values, EC50s for the most sensitive endpoints for each species are expressed as $\mu \mathrm{mol} / \mathrm{L}$. The most sensitive and least variable endpoints for D. magna, C. tentans, and L. gibba were immobility, ash-free dry weight (growth), and dry weight (growth), respectively.

Our results indicate that acute toxicity of the telomer acids to D. magna, C. tentans, and L. gibba is species-dependent and varies with fluorocarbon (FC) chain length and saturation of the $\alpha-\beta$ carbon bond. In general, all three species were most sensitive to telomer acids with chain lengths $\geq 8$ FCs (Figure 2). L. gibba was the most sensitive of the three species to telomer acids of chain lengths $\leq 8 \mathrm{FCs}$, while neither of the invertebrates was particularly sensitive to those with $<8$ FCs. $D$. magna was the most sensitive organism to telomer acids of chain lengths $>8$ FCs. In all three species, toxicity increased with increasing chain length from 6-8 FCs (Figure 2). This trend continued in the case of $D$. magna through FC chain lengths of 10. D. magna was approximately 10 times more sensitive to the 10:2 FTUCA (EC50 immobility $=0.28 \mathrm{mg} / \mathrm{L}$ ) and 100 times more sensitive to the 10:2 FTCA (EC50 immobility $=0.03 \mathrm{mg} / \mathrm{L}$ ) than to either of the $8: 2$ telomer acids. Increasing toxicity with greater chain lengths was not observed for $C$. tentans or L. gibba beyond the 8:2 telomer acids. For C. tentans, the toxicity of the 10:2 FTUCA (EC50 ash-free dry weight $=6.4 \mathrm{mg} / \mathrm{L}$ ) was similar to that for the 8:2 FTCA, and actually increased (EC50 ash-free dry weight $>16 \mathrm{mg} / \mathrm{L}$ ) for the 10:2 FTCA (Figure 2). For L. gibba, EC50s for dry weight $(\mathrm{dw})$ for the 10:2 FTUCA and FTCA were approximately triple those of the 8:2 FTCA (EC50 dry weight $=1.4 \mathrm{mg} / \mathrm{L}$ ).

In general, the saturated forms of the telomer acids were more toxic than their unsaturated counterparts (Figure 2). Exceptions were the 8:2 telomer acid for L. gibba and the 10:2 telomer acid for L. gibba and C. tentans where the unsaturated forms elicited responses similar to or slightly greater than their saturated counterparts. For D. magna, differences in relative toxicity between the 8:2 FTCA and 8:2 FTUCA were less pronounced than those between the 10:2 FTCA and 10:2 FTUCA, with the latter differing by an order of magnitude.

The influence of FC chain length on relative toxicity has also been observed in aquatic organisms for the closely related perfluorinated carboxylic acids (PFCAs). This was demonstrated in previous studies conducted in our laboratories by Boudreau et al. (32). These studies examined the relative toxicity of seven PFCAs with carbon (C) chain lengths of 3-10 on the algae Chlorella vulgaris and Selenastrum capricornutum (Pseudokirchneriella subcapitata), as well as Daphnia magna, D. pulicaria, and L. gibba. In those studies, no toxic effects were reported for any test species, under either laboratory or semifield (mesocosm) conditions, for the 4-7-C PFCAs at concentrations up to $1000 \mathrm{mg} / \mathrm{L}$. However, significant decreases in growth were observed for both algal species and $L$. gibba with exposure to the 3-C and 8-10-C PFCAs. L gibba was the most sensitive of the photosynthetic species with EC50s (wet weight) of 248 and $192-193 \mu \mathrm{mol} / \mathrm{L}$ for the 3-C and 8-10-C PFCAs, respectively. While the current study revealed that L. gibba was sensitive to all the telomer acids tested, the relative impact on growth (i.e., dry weight and frond number) was also greatest for acids with $\geq 8$ FCs. The exception to this generality was the 6:2 FTCA, which was similar in toxicity to the 8:2 FTCA. EC50s for $L$. gibba dry weight ranged from $25.7 \mu \mathrm{mol} / \mathrm{L}(6.6 \mathrm{mg} / \mathrm{L})$ for the $4: 2$ FTUCA to $1.6 \mu \mathrm{mol} / \mathrm{L}(0.92 \mathrm{mg} / \mathrm{L})$ for the $8: 2$ FTUCA, approximately 10-100 times lower for the telomer acids than those reported by Boudreau et al. (32) for PFCAs of corresponding chain lengths. In the Boudreau et al. studies (32), the two daphnid species only showed sensitivity to PFCAs $\geq 8$ Cs in length. Similarly, D. magna in the current study was sensitive only to telomer acids with $\geq 8$ FCs. However, EC50 values for immobility were up to 10000 times smaller than those of the PFCAs, ranging from 8.8 to 0.04 $\mu \mathrm{mol} / \mathrm{L}$ (4.0 to $0.03 \mathrm{mg} / \mathrm{L}$ ) for the 8:2 FTUCA and 10:2 FTCA, respectively. Similarly, $C$. tentans showed little sensitivity in the present study to the shortest chain telomer acids, and were most impacted by those with $\geq 8$ FCs. EC50s for growth ranged from 167 to $12.3 \mu \mathrm{mol} / \mathrm{L}$ (63 to $5.9 \mathrm{mg} / \mathrm{L}$ ) for the $6: 2$ FTCA and 8:2 FTCA, respectively. In general, the findings of the current study agree with those of Boudreau et al. (32) in demonstrating that primary and secondary aquatic species are most sensitive to perfluorinated and telomer acids of 
$\geq 8 \mathrm{C}$ and $\geq 8 \mathrm{FC}$, respectively. The photosynthetic organisms in both studies were also impacted by shorter chain homologs including the 3-C PFCA and the 4-6-FC telomer acids. Our results show that, depending on the species and FC chain length, the telomer acids are $1-4$ orders of magnitude more toxic in terms of their respective EC50s than the PFCAs.

The trends demonstrating the influence of FC chain length on toxicity observed in the current study have also been documented for PFCAs in mammals and fish. Upham et al. (33) found that only PFCAs with chain lengths of 7-10 C inhibited gap junction intercellular communication in rat liver epithelial cells. Furthermore, the degree of inhibition increased with increasing chain length (33). Goek et al. (34) and Goeke-Flora and Reo (35) found that only PFCAs with carbon chain lengths $\geq 8$ induced liver peroxisome proliferation in male rates. Similarly, Intrasuksri and Feller (36) found that PFCAs of $\geq 8 \mathrm{C}$ were the most potent peroxisome proliferators in cultured rat hepatocytes.

Increasing FC chain length directly impacts the physical and chemical properties of both the PFCAs and telomer acids, resulting in decreasing aqueous solubility and volatility, and increasing chemical stability (10). The increasing hydrophobicity imparted by longer FC chain lengths leads to greater bioaccumulation of PFCAs (37), and has been cited as an explanation for longer retention times and slower depuration rates from the bodies of both mammals and fish $(34,35,37)$. It does not seem unreasonable then, that the greater toxicity observed for PFCAs and telomer acids of longer chain lengths might, in part, be the result of greater bioaccumulation and slower depuration rates. However, body burdens could not be determined in test organisms at the time of this work, as no method was available for analyzing telomer acids in such small amounts of tissue.

Although evidence suggests that telomer acids are continually entering aquatic environments $(1,2,14,17)$, their toxicity to aquatic organisms had not been quantified before now. Unfortunately, there are few reported measurements of telomer acids in the environment, and none to date in surface waters. Therefore, the potential risks posed by these compounds to aquatic ecosystems cannot be adequately evaluated at the present time. However, based on currently available measured telomer acid concentrations in rain (17, 18) and PFCA concentrations in surface water $(5,6,8,9)$, it is reasonable to assume that telomer acids are likely present in surface waters in the $\mathrm{ng} / \mathrm{L}$ range. Under this assumption, environmental concentrations are 3 orders of magnitude lower than the acute toxicity thresholds observed in the current study. While concentrations of telomer acids in aquatic systems are likely very small, it is important to recognize the continuous and potentially cumulative nature of inputs to aquatic environments. Since aquatic organisms are likely exposed to telomer acids over their lifetimes, the potential for chronic sublethal effects at lower threshold concentrations than observed here must be considered. Life cycle assays conducted with $D$. magna and C. tentans in our laboratory (38) indicate that chronic toxicity thresholds are lower than the acute thresholds established here. However, the data do not suggest that chronic effects would be anticipated at expected environmental concentrations of the telomer acids.

A limitation of the current study is the lack of measured tissue concentrations of the telomer acids in the test organisms. Unfortunately, the analytical methodology for quantifying telomer acids in tissues did not exist at the time that this work was conducted. However, since the completion of our current work, analytical method development has enabled measurement of the telomer acids in aquatic mammals, where larger amounts of tissue are available. Both the $8: 2$ and 10:2 telomer acids have been measured in bottlenose dolphins (19) and arctic ringed seals (20) at concentrations ranging from 1 to $9.6 \mathrm{ng} / \mathrm{g}$ (ww). The toxicological implications of these tissue residues are not currently known.

The potential implications of the current work may not be limited to aquatic ecosystems. Our data raise larger concerns regarding the in vivo biotransformation of the FTOHs to intermediates that may be more toxic than the end products (PFCAs) that have received much greater attention from a scientific and regulatory perspective. Recent metabolic studies with rat hetapocytes showed that the 8:2 FTOH is oxidized first to the transient 8:2 fluorotelomer aldehyde (8:2 FTAL), which is then oxidized to the unsaturated aldehyde (8:2 FTUAL) or the 8:2 FTCA (39). Either of these may be further oxidized to the 8:2 FTUCA. The eventual fate of the unsaturated metabolites (8:2 FTUAL and 8:2 FTUCA) was reaction with glutathione. Based on their reactivity with glutathione, Martin et al. hypothesized that the 8:2 FTUAL and 8:2 FTUCA may also react with other cellular nucleophiles such as cystein, lysine, histidine, and nucleic acids. This is significant because even a small amount of such nonspecific reactivity with cellular proteins could lead to toxicity (39).

Evidence for biotransformation of the FTOHs to the FTCAs and FTUCAs exists for both microbes $(2,3,21)$ and mammals, both in vivo (40) and in vitro (38), and it likely occurs in all exposed organisms, including humans. Our data, therefore, suggest that further consideration of the toxicology of telomer acids is warranted.

\section{Acknowledgments}

We gratefully acknowledge the financial support of the Natural Science and Engineering Research Council of Canada through a strategic grant awarded to S.A. Mabury and a postgraduate scholarship awarded to M.M. (MacDonald) Phillips.

\section{Supporting Information Available}

Additional details on the experimental procedure, assay conditions, test solution preparation, residue analysis, and experimental results. This material is available free of charge via the Internet at http://pubs.acs.org.

\section{Literature Cited}

(1) Ellis, D. A.; Martin, J. W.; De Silva, A. O.; Mabury, S. A.; Hurley, M. D.; Sulbaek Andersen, M. P.; Wallington, T. J. Degradation of fluorotelomer alcohols: A likely atmospheric source of perfluorinated carboxylic acids. Environ. Sci. Technol. 2004, 38, 3316-3321.

(2) Dinglasan, M. J.; Ye, Y.; Edwards, E. A.; Mabury, S. A. Fluorotelomer alcohol biodegradation yields poly- and perfluorinated aids. Environ. Sci. Technol. 2004, 38, 2857-2864.

(3) Wang, N.; Szostek, B.; Folsom, P. W.; Sulecki, L. M.; Capka, V.; Buck, R. C.; Berti, W. R.; Gannon, J. T. Aerobic biotransformation of ${ }^{14} \mathrm{C}$-labeled 8-2 telomer B alcohol by activated sludge from a domestic sewage treatment plant. Environ. Sci. Technol. 2005, 39, $531-538$

(4) Kubwabo, C.; Vais, N.; Benoit, F. M. A pilot study on the determination of perfluorooctanesulfonate and other perfluorinated compounds in blood of Canadians. J. Environ. Monit. 2004, 6, 540-545.

(5) Moody, C. A.; Martin, J. W.; Kwan, W. C.; Muir, D. C. G.; Mabury, S. A. Monitoring perfluorinated surfactants in biota and surface water samples following an accidental release of fire-fighting foam into Etobicoke Creek. Environ. Sci. Technol. 2002, 36, 545551 .

(6) Martin, J. W.; Whittle, M. D.; Muir, D. C. G.; Mabury, S. A. Perfluoroalkyl contaminants in a food web from Lake Ontario. Environ. Sci. Technol. 2004, 38, 5379-5385.

(7) Martin, J. W.; Smithwick, M. M.; Braune, B. M.; Hoekstra, P. F.; Muir, D. C. G.; Mabury, S. A. Identification of long-chain perfluorinated acids in biota from the Canadian Arctic. Environ. Sci. Technol. 2004, 38, 373-380.

(8) Kannan, K.; Tao, L.; Sinclair, E.; Pastva, S. D.; Jude, D. J.; Giesy, J.P. Perfluorinated compounds in aquatic organisms at various trophic levels in a Great Lakes food chain. Arch. Environ. Contam. Toxicol. 2005, 48, 559-566. 
(9) So, M. K.; Taniyasu, S.; Yamashita, N.; Giesy, J. P.; Zheng, J.; Fang, Z.; Im, S. H.; Lam, P. K. S. Perfluorinated compounds in coastal waters of Hong Kong, South China, and Korea. Environ. Sci. Technol. 2004, 38, 4056-4063.

(10) Kissa, E. Fluorinated Surfactants and Repellents, 2nd ed.; Marcel Dekker, Inc.: New York, 2001; Vol. 97.

(11) DuPont. DuPont Global PFOA Strategy, Presentation to the USEPA, January 31, 2005. In USEPA Office of Pollution Prevention and Toxics. Public Docket; AR226-1914; 2005.

(12) Ellis, D. A.; Martin, J. W.; Hurley, M. D.; Sulbaek Andersen, M. P.; Wallington, T. J. Atmospheric lifetime of fluorotelomer alcohols. Environ. Sci. Technol. 2003, 37, 3816-3820.

(13) Stock, N. L.; Lau, F. K.; Ellis, D. A.; Martin, J. W.; Muir, D. C. G.; Mabury, S. A. Polyfluorinated telomer alcohols and sulfonamides in the North American troposphere. Environ. Sci. Technol. 2004, 38, 991-996.

(14) Dinglasan-Panlilio, M. J. A.; Mabury, S. A. Significant residual fluorinated alcohols are present in fluorinated polymers. Environ. Sci. Technol. 2005, In Press.

(15) Martin, J. W.; Muir, D. C. G.; Moody, C. A.; Ellis, D. A.; Kwan, W. C.; Solomon, K. R.; Mabury, S. A. Collection of airborne fluorinated organics and analysis by gas chromatography/ chemical ionization mass spectrometry. Anal. Chem. 2002, 74, $584-590$.

(16) Hurley, M. D; Ball, J. C.; Wallington, T. J.; Sulbaek Andersen, M. P.; Ellis, D. A.; Martin, J. W.; Mabury, S. A. Atmospheric chemistry of 4:2 fluorotelomer alcohol $\left(\mathrm{CF}_{3}\left(\mathrm{CF}_{2}\right)_{3} \mathrm{CH}_{2} \mathrm{CH}_{2} \mathrm{OH}\right)$ : Products and mechanism of $\mathrm{Cl}$ atom initiated oxidation. J. Phys. Chem. A 2004, 108, 5635-5642.

(17) Loewen, M.; Halldorson, T.; Wang, F.; Tomy, G. Fluorotelomer carboxylic acids and PFOS in rainwater from an urban center in Canada. Environ. Sci. Technol. 2005, 39, 2944-2951.

(18) Scott, B. F.; Spencer, C.; Mabury, S. A.; Muir, D. C. G. Poly and perfluorinated carboxylates in North American precipitation. Environ. Sci. Technol. 2006, 40, 7167-7174.

(19) Houde, M.; Martin, J. W.; Letcher, R. J.; Solomon, K.; Muir, D. C. G. Biological monitoring of polyfluoroalkyl substances: A review. Environ. Sci. Technol. 2006, 40, 3463-3473.

(20) Butt, C.; Muir, D. C. G.; Stirling, I.; Kwan, M.; Mabury, S. A. Rapid response of arctic ringed seals to changes in perfluoroalkyl production. Environ. Sci. Technol. 2007, 41, 42-49.

(21) Lange, C. C. Biodegradation screen study for telomer-type alcohols, 3M Environmental Laboratory. In USEPA Public Docket; AR-226-0555; 2002.

(22) Gauthier, S. A.; Mabury, S. A. Aqueous photolysis of 8:2 fluorotelomer alcohol. Environ. Toxicol. Chem. 2005, 24, 18371846.

(23) Achilefu, S.; Mansuy, L.; Selve, C.; Thiebaut, S. Synthesis of 2H,$2 \mathrm{H}$-perfluoroalkyl and $2 \mathrm{H}$-perfluoroalkenyl carboxylic acids and amides. J. Fluorine Chem. 1995, 70, 19-26.

(24) EC. Biological Test Method: Acute Lethality Test Using Daphnia spp; Environmental Protection, Conservation and Protection, Environment Canada: Quebec, 1990.

(25) MacDonald, M. M.; Warne, A. L.; Stock, N. L.; Mabury, S. A.; Solomon, K. R.; Sibley, P. K. Toxicity of perfluorooctane sulfonic acid and perfluorooctanoic acid to Chironomus tentans. Environ. Toxicol. Chem. 2004, 23, 2116-2123.

(26) Greenberg, B. M.; Huang, X.; Dixon, D. G. Applications of the aquatic higher plant Lemna gibba for ecotoxicological assessment. J. Aquat. Ecosyst. Health 1992, 1, 147-155.

(27) ASTM. Standard guide for conducting static toxicity tests with Lemna gibba G3. Designation: E 1415 - 91. In Annual Book of
ASTMStandards, 11 ed.; ASTM: West Conshohocken, PA, 2001; Vol. 11.05, pp 753-762.

(28) ASTM. Standard guide for conducting acute toxicity tests on test materials with fishes, macroinvertebrates, and amphibians. Designation: E729-96. In Annual Book of ASTM Standards, 11 ed.; ASTM: West Conshohocken, PA, 2001; Vol. 11.05, pp 175196.

(29) EC. Biological Test Method: Reference Method for Determining Acute Lethality of Effluents to Daphnia magna. Method Development and Applications Section; Environmental Technology Centre, Environment Canada: Quebec, 2000.

(30) ASTM. Test method for measuring the toxicity of sedimentassociated contaminants with freshwater invertebrates. Designation: E 1706-00. In Annual Book of ASTM Standards: Water and environmental technology, 11 ed.; ASTM: West Conshohocken, PA, 2001; Vol. 11.05, pp 1109-1225.

(31) Stephenson, G.; Koper, N.; Atkinson, G.; KR, S.; Scroggins, R. Use of nonlinear regression techniques for describing concentration-response relationships of plant species exposed to contaminated soils. Environ. Toxicol. Chem. 2000, 19, 29682981.

(32) Boudreau, T. M.; Sibley, P.; Mabury, S. A.; Muir, D. C. G. Solomon, K. Toxicity of Perfluoroalkyl Carboxylic Acids of Different Chain Length to Selected Freshwater Organisms. In Department of Environmental Biology, Master's Thesis; University of Guelph: Guelph, ON, 2002; p 134.

(33) Upham, B. L.; Deocampo, N. D.; Wurl, B.; Trosko, J. E. Inhibition of gap junction intercellular communication by perfluorinated fatty acids is dependent on the chain length of the fluorinated tail. Int. J. Cancer 1998, 78, 491-495.

(34) Goecke, C. M.; Jarnot, B. M.; Reo, N. V. A comparative toxicological investigation of perfluorocarboxylic acids in rats by fluorine-19 NMR spectroscopy. Chem. Res. Toxicol. 1992, 5, $512-519$.

(35) Goecke-Flora, C. M.; Reo, N. V. Influence of carbon chain length on the hepatic effects of perfluorinated fatty acids. A ${ }^{19} \mathrm{~F}$ - and ${ }^{31}$ P-NMR investigation. Chem. Res. Toxicol. 1996, 9, 689-695.

(36) Intrasuksri, U.; Feller, D. R. Comparison of the effects of selected monocarboxylic, dicarboxylic and perfluorinated fatty acids on peroxisome proliferation in primary cultured rat hepatocytes. Biochem. Pharm. 1991, 42, 184-188.

(37) Martin, J. W.; Mabury, S. A.; Solomon, K. R.; Muir, D. C. G. Bioconcentration and tissue distribution of perfluorinated acids in rainbow trout (Oncorhynchus mykiss). Environ. Toxicol. Chem. 2003 a, 22, 196-204.

(38) MacDonald, M. M. Fluorotelomer Acid Toxicity to Aquatic Organisms. M.Sc. Thesis. University of Guelph, Guelph, Ontario, Canada, 2005

(39) Martin, J. W.; Mabury, S. A.; O’Brien, P. J. Metabolic products and pathways of fluorotelomer alcohols in isolated rat hepatocytes. Chem.-Biol. Interact. 2005, 155, 165-180.

(40) Hagen, D. F.; Belisle, J.; Johnson, J. D.; Venkateswarlu, P. Characterization of fluorinated metabolites by a gas chromatographic helium microwave plasma detector-The biotransformation of $1 \mathrm{H}, 1 \mathrm{H}, 2 \mathrm{H}, 2 \mathrm{H}$-perfluorodecanol to perfluorooctanoate. Anal. Biochem. 1981, 118, 336-343.

Received for review March 27, 2007. Revised manuscript received July 31, 2007. Accepted August 9, 2007.

ES070734C 